\title{
Comunicação-ética-integridade, uma luz para a compreensão dos fenômenos organizacionais no tempo-espaço
} contemporâneo

Communication-ethics-integrity, a light for the understanding of organizational phenomena in contemporary time-space

Comunicación-ética-integridad, una luz para la comprensión de los fenómenos organizacionales en el tiempo-espacio contemporáneo

0 s estudos de ética organizacional, integridade, compliance, bem como de suas interfaces interdisciplinares, têm sido ampliados diante dos desafios econômicos, políticos, socioculturais, tecnológicos e organizacionais que marcam a transição entre os séculos XX e XXI. Esse contexto, marcado por cenários instáveis e crises de credibilidade e confiança nos setores público e privado, fomenta novos olhares e novas abordagens de estudo nos campos de comunicação organizacional e de relações públicas, bem como de outros das ciências sociais e humanas.

Por um lado, observam-se as pressões sociais de grupos impactados direta ou indiretamente pela atitude moral de indivíduos e organizações. Por outro, os movimentos legais de fiscalização e julgamento de crimes de responsabilidade impulsionam e transformam o cenário nacional e internacional. Nesse sentido, os campos da comunicação e da cultura organizacional são eixos de destaque para identificação e análise tanto de processos e fenômenos relacionados à significação, 
à conscientização, ao conhecimento, à atitude e ao comportamento dos indivíduos que compõem as organizações como também das influências desses fenômenos no mundo social.

A edição n. 27 de Organicom - Revista Brasileira de Comunicação Organizacional e Relações Públicas - traz um dossiê sobre comunicação, ética e integridade. Os sete artigos inscritos nessa seção abordam aspectos diversos que revelam a complexidade dos dilemas enfrentados por indivíduos, organizações e pela sociedade no cenário contemporâneo. Nesse sentido, são imensos os desafios éticos que permeiam a dimensão institucional e estrutural de um mundo essencialmente organizacional, mas principalmente humano.

A necessidade de se ampliar a discussão sobre o tema se revela de variadas formas. Uma delas é a mera observação empírica dos fatos políticos, econômicos, sociais e ecológicos, entre outros tantos que nos afetam diariamente, seja por meio de noticiários, mídias sociais ou simplesmente nos encontros informais do dia a dia. Outra é o crescente espaço conquistado pelo assunto em diferentes fóruns e instâncias acadêmicas e em organizações sociais emergentes. Mas, sobretudo, a urgência de mais pesquisa nessa área se manifesta na carência de estudos não apenas teóricos, mas também de gênese empírica, associando ou buscando conexões mais claras entre os conceitos de comunicação, ética e integridade, essa tríade que guarda inúmeras possibilidades de reflexão e teorização.

Diante disso, esse dossiê é uma centelha e traz contribuições relevantes para iluminar os vínculos entre comunicação-éticaintegridade, termos que são, cada um à sua maneira, um mundo a desvendar. Juntos, são uma metagaláxia que reúne as dimensões física, humana e simbólica, um universo a ser desvelado com rigor e sensibilidade; com compreensão.

Em Alteridade, ética e integridade em um mundo de consumidores: o que o caso "Me Gusta Picolés Artesanais" nos ensina?, Marcelo Silva, Jéssica de Cássia Rossi e Ana Carolina Trindade reiteram a importância da bidirecionalidade na comunicação organizacional, defendendo que o diálogo entre organizações e públicos transcenda a comunicação funcional e seja estímulo para o respeito e a compreensão.

Victor Theodoro e Gisela Gonçalves apresentam o estudo Ética das Relações Públicas: os casos da Public Relations Reviewe Journal of Public Relations Research cujo objetivo é compreender a importância atribuída à investigação em ética nos dois periódicos selecionados, considerando o período entre 2000 e 2015. Por meio de método bibliométrico, a pesquisa revela que ética ainda é um tema pouco discutido nessas revistas científicas especializadas muito relevantes na área. Entre outros achados, a investigação revela que, entre os 1.109 artigos publicados no período, apenas 72 (6,5\%) trabalharam a temática. Apesar disso, a análise indica que houve aumento considerável do número de publicações sobre ética nos últimos cinco anos, principalmente na Public Relations Review.

Em Ética, política e religião nas conversações on-line sobre laicidade e diversidade em demandas morais por justiça, Bruno Guimarães e Ângela Marques analisam as interações de pessoas comuns em plataformas midiáticas on-line tomando como base uma notícia acerca de reivindicações de LGBTQ por respeito à diversidade e à laicidade do Estado. 0 artigo busca entender em que medida a relação entre religião e política se constitui nas trocas conversacionais, isto é, observar as formas como os modos de operação da política são postos em disputa e são midiática e discursivamente tensionados. Trata-se de compreender, portanto, quais são as concepções trazidas à tona por esses públicos que oferecem contornos éticos aos embates na internet ao se engajarem em disputas de sentido em torno da relação entre religião e política nos meandros da sociedade brasileira.

O ensaio Vigilância e relações de poder nas redes sociais: questões éticas na sociedade contemporânea, proposto por Leandro Chevitarese e Fábio Medeiros da Rosa, discute o papel das redes sociais na internet, apresentando uma leitura filosófica desse fenômeno social e suas implicações sobre as questões de liberdade e vigilância. 0 texto busca cotejar as reflexões 
dessa análise com as características identificadas em duas grandes redes sociais digitais escolhidas como pano de fundo para a reflexão proposta: Facebook e Snapchat.

Em Ética e as organizações: narrativas e conflitos, Paulo Nassar e Luiz Alberto de Farias fazem uma reflexão sobre as relações entre ética, narrativas organizacionais e responsabilidade sócio-histórica com base em um recorte conceitual e referências marcantes principalmente no campo da filosofia grega, inglesa e alemã, trazendo à tona os conflitos entre o discurso e as decisões e práticas organizacionais. Também projeta as tendências do capitalismo, uma vez que a ética se torna um ativo vital para a diferenciação das empresas no século XXI, e revela a pluralidade de visões éticas, sempre convergindo (e pondo em questão) os conceitos de bem e de felicidade. Os autores advogam que a identidade organizacional esteja sedimentada 0 suficiente para que as empresas estejam sintonizadas com as amplas transformações da ecologia social, cultural e econômica a que se vinculam. Nesse sentido, a ética do mundo de hoje é vista como sinônimo de solidariedade.

Nesta edição, duas entrevistas iluminam a discussão sobre comunicação. A entrevista com Antonio Castillo Esparcia, realizada por María Antonieta Rebeil Corella, oferece uma visão contemporânea do status de relações públicas diante de temas como lobby e interesse público. Já a entrevista com Reynaldo Goto, diretor de Compliance da Siemens no Brasil, foi realizada por Agatha Paraventi e Else Lemos e está diretamente vinculada à temática do dossiê desta edição, discutindo interfaces entre compliance, integridade, comunicação e cultura.

Na seção Pesquisa, o artigo La comunicación interna y el desarrollo humano en el sector restaurantero regional en Yucatán, México, de Rebeca Martínez, apresenta os resultados de estudo quantitativo realizado com os colaboradores de três restaurantes de comida regional de Yucatán, buscando ligações entre a comunicação e uma cultura organizacional que gere representações vinculadas a tradições regionais e, também, ao desenvolvimento humano.

Como ambiente franqueado aos pesquisadores, Organicom mantém o Espaço Aberto, seção dedicada às mais variadas temáticas dos campos da Comunicação Organizacional e Relações Públicas. Nesta edição, três artigos compõem esse núcleo cujos temas destacados envolvem identidade, reputação e responsabilidade social. A presença das redes sociais digitais também garante seu espaço.

Em Presença, identidade e reputação: estratégias de comunicação das empresas blumenauenses nas redes sociais digitais, Fabrícia Zucco, Rafael Jose Bona e Marina Testoni analisam estratégias de uso das redes sociais digitais por empresas de Blumenau/SC, tomando como base a teoria dos Blocos de Construções Funcionais. A pesquisa, de natureza qualitativa, envolveu sete empresas da região de Blumenau e realça os desafios que separam presença - estar inseridas - e preparo conhecer - para atuar nos ambientes digitais.

Em Storytelling corporativo y responsabilidad social empresarial: análisis del caso "The promise", de Volvo, Tomás AtaramaRojas e Carla Sánchez Armas investigam o uso do storytelling como ferramenta para comunicar responsabilidade social. A campanha escolhida foi "The promise", da marca Volvo, buscando-se não apenas compreender o processo empreendido, mas também a ligação entre a narrativa e os valores corporativos.

Encerrando o Espaço Aberto, Magno da Silva e Rudimar Baldissera apresentam Brasilidade, heroísmo, utilidade e necessidade: a construção de um ethos pela propaganda institucional da Petrobras, texto em que discutem a noção de ethos discursivo empregada como tópico analítico por meio do qual se estudam quatro anúncios de propaganda institucional da Petrobras, buscando verificar as estratégias discursivas utilizadas para atualizar e (re)afirmar os atributos de brasilidade, heroísmo e utilidade/necessidade que envolvem a organização. 
A edição 27 conta ainda com três resenhas vinculadas ao tema do dossiê. Em Ética, um bem essencial para uma vida feliz, Denise Pragana apresenta a obra Fundamentos de ética empresarial e econômica, de Maria Cecilia Coutinho de Arruda, Maria do Carmo Whitaker e José Maria Rodriguez Ramos, obra que chegou à 5a edição, atualizada e ampliada, em 2017. Em Um olhar prático para compliance e outros temas ainda obscuros, Fabiana Pinheiro e Ronaldo Rangel analisam o livro Compliance, ética, responsabilidade social e empresarial: uma visão prática, de Luis Roberto Antonik, publicado em 2016. Por fim, em Os caminhos e desafios de uma perspectiva ampla da relação entre ética e comunicação, Camilo Aggio comenta a obra Mídia, ética e esfera pública, de Ângela Marques e Luis Mauro Sá Martino, lançada também em 2016.

Vale destacar que esta edição conta, também, com um depoimento ligado ao tema central do dossiê. Em Programa de integridade: ação, compromisso e transparência, Eduardo Staino, diretor de Compliance da Andrade Gutierrez, explicita e detalha os passos caminhados na edificação de bases sólidas para gestão da integridade nessa grande multinacional brasileira.

Para finalizar, o ensaio Gestão Responsável: responsabilidade, ética e sustentabilidade a partir do PRME, Flávio Hourneaux Jr. e Adriana Caldana tratam dos desafios para fomentar e manter a Gestão Responsável, tendo como referência o Principles for Responsible Management Education (PRME), assunto que também foi abordado por Reynaldo Goto, entrevistado nesta edição.

Desejamos que esta edição seja um estímulo ao surgimento de novas argumentações e controvérsias e que abra espaço para mais comunicação-ética-integridade não só na teoria, mas na prática.

Boa leitura! 